\title{
THE RESEARCH AND IMPLEMENTATION OF Passenger Car's Transportation PlanNing PROBLEM
}

\author{
Chen Zhang, Xiaoming You and Kai Liu \\ College of Electronic and Electrical Engineering, Shanghai University of Engineering \\ Science, Shanghai 201620, China
}

\begin{abstract}
In order to solve the problem of providing a detailed plan of passenger car's loading scheme for the transportation company, and to provide general program for transportation planning, the blanking model of solving the loading problem is established.First by giving the load model of single-deck and single-row car, then established the blanking model for the decision variables by taking model number, so that can solve the problem of arbitrary loading values. The numerical calculation of blanking model has discussed specially, and by making corresponding program, the loading plan of passenger car that to solve the problem has been given.
\end{abstract}

\section{KEYWORD}

transportation, optimums, passenger car, program, vehicle logistics

\section{INTRODUCTION}

With the rapid development of the national economy and the continuous improvement of people's living standards, the demand for automobile consumption rising. Along with the increase in the demand for cars at home and abroad, led to the rapid growth of the car production, and the rapid expansion of the car market also pull the rapid development of automobile logistics industry, For the rapid rise of the automobile logistics industry in China provides an unprecedented development opportunities and challenges[1].

Such opportunities for the development of Chinese automobile logistics industry provides a good development space[2], Will also be faced with many challenges. Usually on the premise of ensure transportation task, logistics company to pursue lower transportation costs. But due to its transport vehicles, passenger vehicles have a variety of specifications and other reasons, many current logistics company in transportation planning and scheduling personnel mainly depends on experience, In the face of the complex transport task, are often inefficient, and transportation cost is not ideal. We must use existing data one thousand ways to carry out scientific research, and use the creative thinking to explore new methods in a more efficient to solve the problem.

The main problem is heterogeneous car routing problem with two-dimensional loading constraint, first its car carrier loading scheme is put forward, then planning path and unloading way makes its car carrier usage is minimal, A particular type of car is less, The total mileage traveled at least. To solve the problem of using the discharge model is established [3], finally based on this model, 
Computer Science \& Engineering: An International Journal (CSEIJ), Vol.5, No.4, August 2015

then corresponding the program, at the same time also give the calculation process of the model. Specifically discussed the numerical calculation of blanking model, and integer programming optimization model and application of the problem.

\section{THE QUESTION}

Transport car logistics cost calculation is relatively complex, to simplify.

First of all, influence the cost of high and low is the car carrier use quantity;

The second, under the condition of the same number of the car carrier to use, 1-1 car carrier of low use cost, but the2-2 are higher,1-2 slightly lower than its average of the first two, but logistics company's 1-2 car carrier ownership is too small, In order to facilitate subsequent task arrangement, every 1-2 car transport vehicles use no more than 1-1 car transport vehicle usage of $20 \%$;

Once again, under the condition of the same number and the type of the car carrier to use ,the cost of the short mileage is low, we should pay more attention because of the logistics company is a national company, in all parts have the vehicle logistics business, so after arriving at our destination, the car put on standby, don't need to return empty[4].

At last, the cost of each unloading almost can be ignored.

The question 1:

The logistics company need to transport the type of I passenger vehicles is 100 and the type of II is 68.In order to detail plan for Transportation Company, containing what the need of the quantity of all type of the cars, the passenger car's loading plan of the each car and the route of the car.

The question 2:

The logistics company need to transport the type of II passenger vehicles is 72 and the type of III is 52. In order to detail plan for transportation company, containing what the need of the quantity of all type of the cars, the passenger car's loading plan of the each car and the route of the car.

The question 3:

The logistics company need to transport the type of I passenger vehicles is 156 and the type of the II is 102 and the type of III is 39. In order to detail plan for Transportation Company, containing what the need of the quantity of all type of the cars, the passenger car's loading plan of the each car and the route of the car.

\section{ANALYSIS OF THE QUESTION}

First of all, only considerate how to maximize use of limited carriages, don't need to consider the problem of the car routing . Because of putting the passenger car into the carriage[5], be equal to divide it into different length of segments, each segment can hold a car, considering the safety of the longitudinal distance number of the cars that between adjacent is equal to the section number 
Computer Science \& Engineering: An International Journal (CSEIJ), Vol.5, No.4, August 2015

minus 1 , as long as the segmentation method are given, remove from the carriage, determine the problem of cutting model is established. The second, it will be considered individually the lower level of the type of 1-1 and 1-2, calculate the different types of car transport vehicles loaded with the number of passenger cars each combination, is also give the two types of car loading mode. The different modes of the packing is too much, will lead to complicate the assembly process. In order to provide what set containing the number of all kinds of car transport vehicle, the detailed plan of loading scheme of the passenger car, a kind of assembly scheme is composed of several different patterns that are repeat for sure[6]. If the model number as the decision variables, then according to the number of patterns in a variety of models can know the number of each type of the passenger car, thus, we first need according to the specifications of different type car , Especially the constraints of length of its car carrier(The upper limit is 1.7 meters tall), to solve the problem of using the discharge model is established. Finally based on this model, then corresponding the program[7], at the same time also give the calculation process of the model, and it provide the general procedure for the transportation company that to transport planning .

For the question one, it set the number of passenger cars' input parameter vector to, run the LINGO general program, and get the solution of the model, that is containing the combination of the using number of the different type of the passenger car and the optimal transport scheme of the different types of loading passenger vehicles.

For the question two, it set the number of passenger cars' input parameter vector to, run the LINGO general program, and get the solution of the model, that is containing the combination of the using number of the different type of the passenger car and the optimal transport scheme of the different types of loading passenger vehicles.

For the question one, it set the number of passenger cars' input parameter vector to , run the LINGO general program, and get the solution of the model, that is containing the combination of the using number of the different type of the passenger car and the optimal transport scheme of the different types of loading passenger vehicles.

\section{MODELING AND SOLVING}

At first, in order to determine the number of all kinds of transport vehicle and every car's passenger car loading plan, we need to according to the specifications of the different type of the car[9], especially the limited of the length of the passenger car(the upper limit is 1.7 meters tall), and calculate the model of the different type car carrier compartments that can load per passenger car, then according to the number of the package of each model what meet the constraint conditions, established the blanking optimization model, then list the objective function and constraint conditions. At last based on this model, using the LINGO software to model, and make the transport planning and provide the general procedure for transportation company.

(1) The single-deck and single row loading mode of the two kinds of model car

To solving the blanking model, first drawing when per car are loading, there is how many kinds of possible. The program in appendix give the number of the bottom of the 1-1 type of the car transporter, the top of the 1-1 type of the car transporter, the bottom of the 1-2 type of the car transporter, the top of the 1-2 type of the car transporter and the number of the various kinds of model that loading two columns 1-1 type of the passenger cars, and number the full mode as $1,2, \ldots, 15$ and $1,2, \ldots, 21$ and $1,2, \ldots, 5$ and $1,2, \ldots, 6$ 
(2) Establishing the model

The problem is described as: There are two different models( , 1-1 type ; , 1-2 type) car transporter, the length is , and the number of the each type of the car transporter is , the delivery demand of passenger car is : I type_—, II type_—, III type_— . To solve the combination loading plan that how to plan all kinds of passenger cars in the car transporter, make the car carrier usage at least, at the same condition of the usage, the 1-1 type of the car is smaller. This model set the punishment coefficient of the 1-2 type of the car is 1.1, and establish the objective function of the car carrier is minimum quantity, the established the mathematical models of blanking as shown

below: $\min \left(\sum_{j=1}^{P} x_{j 1}+1.1 \sum_{j=1}^{P} x_{j 2}\right)$

$$
\text { s.t }\left\{\begin{array}{l}
x_{j k}, y_{j k} \text { are int eger } \\
2 \sum_{j=1}^{P_{1}} x_{j 2}=\sum_{j=1}^{P_{2}} y_{j 2}+\sum_{j=1}^{P_{2}} y_{j 3} \\
\sum_{j=1}^{P_{2}} y_{j 2}=\sum_{j=1}^{P_{2}} y_{j 3} \\
\sum_{j=1}^{P_{1}} x_{j 1}=\sum_{j=1}^{P_{2}} y_{j 1} \\
A_{j k}^{i}\left(x_{j k}+y_{j k}\right) \geq d_{i}, i=1,2,3 \\
0.2 \sum_{j=1}^{P_{1}} x_{j 1} \geq \sum_{j=1}^{P_{2}} x_{j 2}
\end{array}\right.
$$

Among them, as the bottom of the $\mathrm{k}$ kind of car that adopt the mode of the $\mathrm{j}$ kind of load, , 1-2 type car carrier the upper two columns calculated separately $(\mathrm{k}=3)$, as the k kind of car singlerow and single-column car that using the $\mathrm{j}$ kind of load model's $\mathrm{i}$ kind of the number of passenger cars.

\subsection{The Solution And Model Of The Question1}

Ordered $d_{1}=100, d_{2}=68, d_{3}=0$

Supposed $A_{1 k}, A_{2 k}$ respectively as the number of the bottom and the top of the load model passenger car, the packing problem can be expressed in blanking model: 
Computer Science \& Engineering: An International Journal (CSEIJ), Vol.5, No.4, August 2015

$$
\text { s.t }\left\{\begin{array}{l}
2 \sum_{j=1}^{21} x_{j 2}=\sum_{j=1}^{6} y_{j 2}+\sum_{j=1}^{6} y_{j 3} \\
\sum_{j=1}^{6} y_{j 2}=\sum_{j=1}^{6} y_{j 3} \\
\sum_{j=1}^{15} x_{j 1}=\sum_{j=1}^{5} y_{j 1} \\
A_{j k}^{i} \geq d_{i}, i=1,2,3 \\
A_{11} x_{j 1}+A_{21} y_{j 1} \geq 100 \\
A_{12} x_{j 2}+A_{22} y_{j 2}+A_{22} y_{j 3} \geq 68 \\
x_{j k}, y_{j k} \text { are int eger } \\
0.2 \sum_{j=1}^{15} x_{j 1} \geq \sum_{j=1}^{21} x_{j 2}
\end{array}\right.
$$

The process of the calculation:

Writing LINGO program, writing the general program of getting transport scheme[8]. Then put the related data into the program, get the use quantity of each type of car carrier and corresponding transportation plan.

Step one: Data in the table, in the shape of the matrix form of , just as $(100,68,0)$,then input the LINGO program that written above.

Table4-1 Input data of the question 1

\section{The passenger car number(type) The number of passenger vehicles to transport}

I 100

II 68

Step two: To run the program.

Step three: Run the program and get the output results.

$x_{1}(5)=9$ is the bottom of the 1-1 type car carrier adopt model 5 to load the number of the passenger cars is $9(0,5,0)$

$x_{1}(15)=7$ is the bottom of the 1-1 type car carrier adopt model 15 to load the number of the passenger cars is $7(4,0,0)$

$y_{1}(1)=4$ is the top of the $1-1$ type car carrier adopt model 1 to load the number of the passenger cars is $15(4,0,0)$ 
Computer Science \& Engineering: An International Journal (CSEIJ), Vol.5, No.4, August 2015

$y_{1}(4)=1$ is the top of the 1-1 type car carrier adopt model 4 to load the number of the passenger cars is $1(1,3,0)$

$x_{2}(15)=1$ is the bottom of the 1-2 type car carrier adopt model 15 to load the number of the passenger cars is $1(2,4,0)$

$x_{1}(19)=1$ is the bottom of the 1-2 type car carrier adopt model 19 to load the number of the passenger cars is $1(4,0,1)$

$y_{2}(3)=y_{3}(3)=2$ is the top of the 1-2 type car carrier adopt model 1 to load the number of the passenger cars is $2(2,4,0)$

So, the demand for the type of $1-1$ car carrier is $D_{1}=9+7=15+1=16$

The demand for the type of $1-2$ car carrier is $D_{2}=1+1=2$

The number of the type of 1-1 car carrier on the top of the passenger car of number $\mathrm{I}$ is $15 \times 4+1 \times 1=61$

The number of the type of $1-1$ car carrier on the top of the passenger car of number $\mathbb{I}$ is $1 \times 3=3$

The number of the type of 1-1 car carrier on the bottom of the passenger car of number $\mathrm{I}$ is $7 \times 4=28$

The number of the type of 1-1 car carrier on the bottom of the passenger car of number $I I$ is $9 \times 5=45$

The number of the type of 1-2 car carrier on the top of the passenger car of number $\mathrm{I}$ is $2 \times 2 \times 2=8$

The number of the type of 1-2 car carrier on the top of the passenger car of number II is $2 \times 2 \times 4=16$

The number of the type of 1-2 car carrier on the bottom of the passenger car of number $\mathrm{I}$ is $1 \times 4+1 \times 2=6$

The number of the type of 1-2 car carrier on the bottom of the passenger car of number II is $1 \times 4=4$

In total, the number of the type of I passenger car is $61+28+8+6=103>100$

The number of the type of II passenger car is $3+45+16+4=68=68$

It meet the transport demand of shipping companies, the specific transportation scheme are shown in table 4-2. 
Computer Science \& Engineering: An International Journal (CSEIJ), Vol.5, No.4, August 2015

Table4-2 the transport plan of the question 1

\begin{tabular}{|c|l|c|l|l|l|}
\hline $\begin{array}{c}\text { the type of } \\
\text { passenger } \\
\text { car }\end{array}$ & $\begin{array}{l}\text { the same } \\
\text { type and the } \\
\text { number of } \\
\text { same } \\
\text { loading way }\end{array}$ & $\begin{array}{l}\text { The number } \\
\text { of top } \\
\text { number I } \\
\text { passenger }\end{array}$ & $\begin{array}{l}\text { The number } \\
\text { of top } \\
\text { number II } \\
\text { passenger } \\
\text { of bottom } \\
\text { number I } \\
\text { passenger }\end{array}$ & $\begin{array}{l}\text { The number number } \\
\text { of bottom } \\
\text { number II } \\
\text { passenger }\end{array}$ \\
\hline $1-1$ & 16 & 61 & 3 & 28 & 45 \\
$1-2$ & 2 & 8 & 16 & 6 & 4 \\
\hline
\end{tabular}

\subsection{The Solution And The Model Of The Question 2}

Let $d_{1}=0, d_{2}=72, d_{3}=52$

With the car carrier number as the objective function. The concrete mathematical model as shown below.

$$
\begin{gathered}
\min \left(\sum_{j=1}^{15} x_{j 1}+1.1 \sum_{j=1}^{21} x_{j 2}\right) \\
\text { s.t }\left\{\begin{array}{l}
2 \sum_{j=1}^{21} x_{j 2}=\sum_{j=1}^{6} y_{j 2}+\sum_{j=1}^{6} y_{j 3} \\
\sum_{j=1}^{6} y_{j 2}=\sum_{j=1}^{6} y_{j 3} \\
\sum_{j=1}^{15} x_{j 1}=\sum_{j=1}^{5} y_{j 1} \\
A_{j k}^{i} \geq d_{i}, i=1,2,3 \\
A_{11} x_{j 1}+A_{21} y_{j 1} \geq 72 \\
A_{12} x_{j 2}+A_{22} y_{j 2}+A_{22} y_{j 3} \geq 52 \\
x_{j k}, y_{j k} \text { are int eger } \\
0.2 \sum_{j=1}^{15} x_{j 1} \geq \sum_{j=1}^{21} x_{j 2}
\end{array}\right.
\end{gathered}
$$

The calculation process

Step one: Data in the table, in the shape of the matrix form of , just as $(0,72,52)$,then input the LINGO program that written above 
Computer Science \& Engineering: An International Journal (CSEIJ), Vol.5, No.4, August 2015

Table4-3 The input data of the question 2

The passenger car number(type) The number of passenger vehicles to transport

II 72

III52

step 2: run the program

step3: run the program's output results

$x_{1}(1)=11$ is the bottom of the 1-1 type car carrier adopt model 1 to load the number of the passenger cars is $11(0,0,4)$

$x_{1}(2)=1$ is the bottom of the 1-1 type car carrier adopt model 2 to load the number of the passenger cars is $1(0,1,3)$

$y_{1}(5)=12$ is the top of the 1-1 type car carrier adopt model 1 to load the number of the passenger cars is $5(0,5,0)$

$x_{2}(1)=1$ is the bottom of the 1-2 type car carrier adopt model 1 to load the number of the passenger cars is $1(0,0,5)$

$y_{2}(1)=y_{3}(1)=2$ is the top of the 1-2 type car carrier adopt model 1 to load the number of the passenger cars is $1(0,6,0)$

So, the demand for the type of $1-1$ car carrier is $D_{1}=11+1=12$

The demand for the type of $1-2$ car carrier is $D_{2}=1$

The number of the type of 1-1 car carrier on the top of the passenger car of number II is $12 \times 5=60$

The number of the type of 1-1 car carrier on the bottom of the passenger car of number II is $1 \times 1=1$

The number of the type of 1-1 car carrier on the bottom of the passenger car of number III is $11 \times 4+1 \times 3=47$

The number of the type of $1-2$ car carrier on the top of the passenger car of number $I I$ is $2 \times 1 \times 6=12$

The number of the type of 1-2 car carrier on the bottom of the passenger car of number III is $1 \times 5=5$

In total, the number of the type of $I$ passenger car is $60+1+12=73>72$

The number of the type of III passenger car is $47+5=52=52$ 
Computer Science \& Engineering: An International Journal (CSEIJ), Vol.5, No.4, August 2015

It meet the transport demand of shipping companies, the specific transportation scheme are shown in table 4-4

Table4-4 the transport plan of question 2.

\begin{tabular}{|c|c|c|c|c|c|}
\hline $\begin{array}{c}\text { the type of } \\
\text { passenger } \\
\text { car }\end{array}$ & $\begin{array}{c}\text { the same type } \\
\text { and the } \\
\text { number of } \\
\text { same loading } \\
\text { way }\end{array}$ & $\begin{array}{c}\text { The } \\
\text { number of } \\
\text { top number } \\
\text { II } \\
\text { passenger }\end{array}$ & $\begin{array}{c}\text { The } \\
\text { number of } \\
\text { top number } \\
\text { III } \\
\text { passenger }\end{array}$ & $\begin{array}{c}\text { The } \\
\text { number of } \\
\text { bottom } \\
\text { number II } \\
\text { passenger }\end{array}$ & $\begin{array}{c}\text { The } \\
\text { number of } \\
\text { bottom } \\
\text { number III } \\
\text { passenger }\end{array}$ \\
\hline $1-1$ & 12 & 60 & 1 & 0 & 47 \\
$1-2$ & 1 & 12 & 0 & 0 & 5 \\
\hline
\end{tabular}

According to the above three question model and validation, prove the complied transportation scheme model and program in this paper, it has strong versatility and feasibility, it can make the optimization transport scheme for transportation company, and it can reduce transportation costs for transportation companies, improve the efficiency of transportation, what is of great significance[9].

\subsection{The Solution And The Model Of The Question 3}

Let $d_{1}=156, d_{2}=102, d_{3}=39$

With the car carrier number as the objective function. The concrete mathematical model as shown below.

$$
\begin{aligned}
& F= \min \sum_{j=1}^{P} x_{j k} \\
& \text { s.t }\left\{\begin{array}{l}
\sum_{j=1}^{P} x_{j k} \leq D_{k}, \mathrm{k}=1,2,3 \\
x_{j k}, \mathrm{y}_{j k} \text { are int eger } \\
\sum_{k=1}^{k} \sum_{j=1}^{P} A_{j k}^{1} x_{j k} \geq 156 \\
\sum_{k=1}^{k} \sum_{j=1}^{P} A_{j k}^{2} x_{j k} \geq 102 \\
\sum_{k=1}^{k} \sum_{j=1}^{P} A_{j k}^{3} x_{j k} \geq 39 \\
0.2 \sum_{j=1}^{P} x_{j 1} \geq \sum_{j=1}^{P} x_{j 2}
\end{array}\right.
\end{aligned}
$$

The calculation process

Step one: Data in the table, in the shape of the matrix form of , just as $(156,102,39)$,then input the LINGO program that written above 
Computer Science \& Engineering: An International Journal (CSEIJ), Vol.5, No.4, August 2015

Table4-5 The input data of the question 3

\begin{tabular}{|cc|}
\hline The passenger car number(type) & The number of passenger vehicles to transport \\
\hline I 156 \\
II 102 \\
III 39 \\
\hline
\end{tabular}

step 2: run the program

step3: run the program's output results

$x_{1}(6)=7$ is the bottom of the 1-1 type car carrier adopt model6 to load the number of the passenger ars is $7(1,0,3)$

$x_{1}(13)=18$ is the bottom of the $1-1$ type car carrier adopt model 13 to load the number of the passenger cars is $18(3,0,1)$

$y_{1}(1)=15$ is the top of the 1-1 type car carrier adopt model 1 to load the number of the passenger cars is $15(4,0,0)$

$y_{1}(2)=2$ is the top of the 1-1 type car carrier adopt model 2 to load the number of the passenger cars is $2(3,1,0)$

$y_{1}(5)=8$ is the top of the 1-1 type car carrier adopt model 5 to load the number of the passenger cars is $8(0,5,0)$

$x_{2}(15)=5$ is the bottom of the 1-2 type car carrier adopt model 15 to load the number of the passenger cars is $5(2,4,0)$

$y_{2}(3)=y_{3}(3)=5$ is the top of the 1-2 type car carrier adopt model 3 to load the number of the passenger cars is $5(2,4,0)$

So, the demand for the type of $1-1$ car carrier is $D_{1}=9+7=15+1=25$

The demand for the type of $1-2$ car carrier is $D_{2}=5$

The number of the type of 1-1 car carrier on the top of the passenger car of number $\mathrm{I}$ is $15 \times 4+3 \times 2=66$

The number of the type of 1-1 car carrier on the top of the passenger car of number $I I$ is $2 \times 1+8 \times 5=42$

The number of the type of 1-1 car carrier on the bottom of the passenger car of number $\mathrm{I}$ is $7 \times 1+18 \times 3=61$

The number of the type of 1-1 car carrier on the bottom of the passenger car of number III is $7 \times 3+18 \times 1=39$ 
The number of the type of 1-2 car carrier on the top of the passenger car of number $\mathrm{I}$ is $2 \times 5 \times 2=20$

The number of the type of 1-2 car carrier on the top of the passenger car of number II is $2 \times 5 \times 4=40$

The number of the type of 1-2 car carrier on the bottom of the passenger car of number $\mathrm{I}$ is $5 \times 2=10$

The number of the type of 1-2 car carrier on the bottom of the passenger car of number $I$ is $5 \times 4=20$

In total, the number of the type of I passenger car is $66+61+20+10=157>156$

The number of the type of II passenger car is $39=39$

It meet the transport demand of shipping companies, the specific transportation scheme are shown in table 4-6

Table4-6 the transport plan of question 3.

\begin{tabular}{|c|c|c|c|c|c|c|c|}
\hline $\begin{array}{l}\text { The } \\
\text { type of } \\
\text { passen } \\
\text { ger car }\end{array}$ & $\begin{array}{c}\text { The } \\
\text { same } \\
\text { type and } \\
\text { the } \\
\text { number } \\
\text { of same } \\
\text { loading } \\
\text { way }\end{array}$ & $\begin{array}{c}\text { The } \\
\text { numbero } \\
\text { f top } \\
\text { number } \\
\text { I } \\
\text { passenge } \\
r\end{array}$ & $\begin{array}{c}\text { The } \\
\text { number } \\
\text { of top } \\
\text { number } \\
\text { II } \\
\text { passenge } \\
\text { r }\end{array}$ & $\begin{array}{c}\text { The } \\
\text { number } \\
\text { of top } \\
\text { number } \\
\text { III } \\
\text { passenge } \\
\text { r }\end{array}$ & $\begin{array}{c}\text { Thenum } \\
\text { ber of } \\
\text { bottom } \\
\text { number } \\
\text { I } \\
\text { passenge } \\
\text { r }\end{array}$ & $\begin{array}{c}\text { The } \\
\text { number } \\
\text { of } \\
\text { bottom } \\
\text { number } \\
\text { II } \\
\text { passenge } \\
\text { r }\end{array}$ & $\begin{array}{c}\text { The } \\
\text { number } \\
\text { of bottom } \\
\text { number } \\
\text { III } \\
\text { passenger }\end{array}$ \\
\hline $1-1$ & 25 & 66 & 42 & 0 & 61 & 0 & 39 \\
\hline $1-2$ & 5 & 20 & 40 & 0 & 10 & 20 & 0 \\
\hline
\end{tabular}

According to the above three question model and validation, prove the complied transportation scheme model and program in this paper, it has strong versatility and feasibility, it can make the optimization transport scheme for transportation company, and it can reduce transportation costs for transportation companies, improve the efficiency of transportation, what is of great significance[10].

\section{THE CONCLUSION}

Model in this paper is considered the most complex situation from the perspective of the three categories passenger car, by using the model to solve the assembly problem, at first, it presented the load model of the single-deck and single-row car, then take model number for the decision variables that established the blanking model, it can solve the problems of load problem that can get arbitrary values, and it was obtained three problems' passenger car loading plan by using LINGO software, further, it need to considered the assembly and routing problems at the same time, and let the optimized model is more efficient and more general. 
Computer Science \& Engineering: An International Journal (CSEIJ), Vol.5, No.4, August 2015

\section{ACKNOWLEDGMENTS}

The authors gratefully acknowledge the support of Innovation Program of Shanghai Municipal Education Commission (Grant No.12ZZ185), Natural Science Foundation of China (Grant No.61075115), Foundation of No. 15KY0201. Xiao-Ming You is corresponding author.

\section{REFERENCES}

[1] Etsuko Niahimura, Akio Imai. Optimal Vehicle Routing For Container Handling In A Multi-User Container Terminal. Published by Kobe University of Mercantile Marine.Kobe. Japan. October 23-25, 2000.

[2] Han Kuk-Hyun, Kim J H. Genetic Quantum Algorithm and Its Application to Combinatorial Optimization Problems[C]//Proc. of IEEE Conference on Evolutionary Computation. Piscataway, USA: IEEE Press, 2000.

[3] Han Kuk-Hyun, Park Kui-Hong, Lee Ci-Ho, et al. Parallel Quantum-inspired Genetic Algorithm for Combinatorial Optimization Problems[C]//Proc. of IEEE Conference on Evolutionary Computation. Piscataway, USA: IEEE Press, 2001.

[4] He J and Yao X.A study of drift analysis for estimating computation time of evolution algorithms[J].Natural Computing,2004,3:21-35.

[5] Kyoung-mo Koo.The Function Of International FreightForwarders:Expended into Third-Party Logistics Provider(3PL Provider).International Seminar On Global Transportation Network. Published by Kobe University of Mercantile Marine.Kobe Japan. October 23-25, 2000.

[6] Narayanan A, Moore M. Quantum-inspired Genetic Algorithm[C]Proc. of IEEE International Conference on Evolutionary Computation. Piscataway, USA: IEEE Press, 1996.

[7] Onald.h.ballou. Business Logistics Management. The Forth Edition. Published by Prentice-Hall International(UK)LimitedLondon. 1999.

[8] Shu-Chu Liu, Chich-Hung Chung. A heuristic method for the vehicle routing problem with backhauls and inventory[J]. Journal of Intelligent Manufacturing,2009,201.

[9] Wang Ling, Tang Fang, Wu Hao. Hybrid Genetic Algorithm Based on Quantum Computing for Numerical Optimization and Parameter Estimation[J]. Applied Mathematics and Computation, 2005, 171(2)1141-1156.

[10] XING H L,PAN W, ZOU X H. A novel improved quantum genetic algorithm for combinatorial optimization Problems[J] .Acta Electronica Sinica,2007,35(10):1999-2002.

\section{Author}

Chen Zhang is currently studying in Mechanical and Electronic Engineering from Shanghai University of Engineering Science, China, where she is working toward the Master degree. Her current research interests include ant colony algorithm, their design and develop in Embedded system.

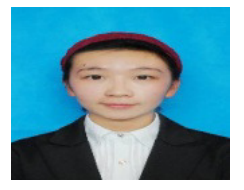

